\title{
Mothers Against Decapentaplegic Homolog 4
}

National Cancer Institute

\section{Source}

National Cancer Institute. Mothers Against Decapentaplegic Homolog 4. NCI Thesaurus. Code $\mathrm{C17982.}$

Mothers against decapentaplegic homolog 4 (552 aa, $60 \mathrm{kDa}$ ) is encoded by the human SMAD4 gene. This protein is involved in cytokine signaling and transcription factor activity. 